\title{
A Gastrostomy in Every Stomach?
}

When caring for older persons, particularly those older than 85 years, the question that physicians must address is not what can be done but what should be done? In every setting in which family physicians practice, a vast array of high-tech medical interventions are available. Their very presence, ease in application, and low inherent risk almost demand their use. Many technological interventions are rapidly adopted by the medical community, even before well-conceived studies of effectiveness and efficacy have been completed. As these procedures become more readily available, the consumer's acceptance of them could soon shift to an expectation that they will be provided. Witness the well-reported controversy about whether physicians in managed care should have restricted access to computed tomographic scans of the brain as part of the workup of headaches. Indeed, a technological imperative is created whereby the existence of an intervention demands its use. ${ }^{1}$

At first glance gastrostomy tubes would hardly seem to be a high-tech intervention. Yet when one considers the marvel of fiberoptic mechanics and the skillful insertion of foreign bodies into the human body, one must admit that percutaneous endoscopic gastrostomy (PEG) is a fantastic development. It has a low mortality rate (estimated at approximately 0.4 percent), ${ }^{2}$ is simple enough to do on an outpatient basis, and is associated with fewer complications than open gastrostomy placement. Perhaps it is this collection of attractive features that has led to the somewhat startling results discussed by Grant in this issue of the JABFP. ${ }^{3}$

Grant found, using data from the National Hospital Discharge Survey, that an estimated 1 percent of the United States population older than 85 years was discharged from a hospital in 1990 with a gastrostomy. Age-specific placement rates varied from 1.2 per 1000 for the so-called youngold (those younger than 65 years) to 10.8 per 1000 for the old-old (those older than 85 years). Rates were also higher in women than in men and two

Submitted 17 December 1997.

From the Long-Term Care Division, Providence Health System, Oregon, 3510 NE 122nd St, Suite 200, Portland, OR 97230 times higher in African-Americans than in whites. Not surprisingly, strokes and neoplasms were frequently listed as primary diagnoses in discharge records. Yet less than one half had swallowing disorders, aspiration pneumonia, or head and neck cancer (accepted indications) listed among seven possible discharge diagnoses. In-hospital mortality was 16 percent. Unfortunately, the data did not allow for analysis of long-term mortality or complications, though it was found that 55 percent of those surviving hospitalization were discharged to long-term care settings.

Since 1988 the number of gastrostomies has grown by 56 percent, exceeding the corresponding high rate of growth of the elderly population. Why is it that PEG placement has become so common? Clearly, it is a less invasive and less dangerous procedure than open gastrostomy. For physicians trained to do something, it offers a quick and simple approach to such complex problems as malnutrition, dysphagia, and anorexia. Indeed, when associated with the act of feeding, it is seen as basic care by many. Clearly, there are good reasons for using gastrostomy tubes in certain patients. The ideal candidate is one who is temporarily unable to consume food by mouth and for whom a protracted recovery is expected. A person who has survived a stroke with dysphagia, who shows early signs of motor recovery, and who has good premorbid cognition would be such a patient.

Yet for those with advanced age gastrostomies have serious risks, risks that might not be fully known by those who recommend it or those who accept its use. Ciocon et al ${ }^{4}$ showed that as many as 44 percent of patients provided gastrostomy tubes developed agitation leading to extubation. Often this response initiates a cascade of disasters whereby the patient is restrained, either physically or chemically, which increases the risk for iatrogenic complications. Gastrostomies are often provided to prevent pneumonia in cases where there is the threat of aspiration. Yet many studies have documented a rate of aspiration pneumonia after gastrostomy tube placement that ranges from 8 to 56 percent. ${ }^{46}$

Even the question of whether gastrostomy tube 
placement increases survival is controversial. Some studies report hospital mortality rates as high as $\mathbf{2 5}$ percent, while others show long-term survival to be from an median of 7.5 months to 2 years. ${ }^{7}$ It appears that the average rate of survival at 1 year for very elderly patients for whom PEG is being considered is about 50 percent, with or without the tube. For those older than 75 years, the median survival from time of tube placement is only 5.7 months. ${ }^{5}$

Another risk to the placement of gastrostomy tubes in older adults with serious neurologic diseases is that it will become the standard of care. In a study by Golden et al, ${ }^{7}$ the average age of the 102 nursing home residents who received a PEG tube was 89.3 years. Eighty-seven percent had severe dementia (clinical dementia rating scale, grade 3 ). Seventy-five percent were totally dependent in all activities of daily living. As stated by Pick et alt:

Nutrition is a major problem in patients with dysphagic syndromes, and invasive nutritional interventions with nasogastric, gastric, and jejunal tubes become the rule....

The inability to take in enough nutrition to satisfy the body's needs is indeed the rule in almost all chronically debilitating diseases that lead to death. As such, that inability can be viewed as a part of the natural history of the dying process. Are we as a society willing to accept the medicalization of death by expecting that all elders unable to swallow must be offered the invasion of having a tube inserted into their belly?

What are the alternatives? First, we need clearer guidelines and a consensus on choosing candidates for gastrostomy tube placement. Second, we as physicians need to be honest and forthright in discussing the issue of terminal feeding with patients and their families. For example, all patients with end-stage dementia will become dysphagic. When is the best time to bring up a discussion of the use of feeding tubes? Some fear that bringing it up early will throw the patient into a depression and could even lead them to commit suicide. Yet if it is not addressed when the patient still has decision-making capacity, the opportunity for having the patient make an informed decision is lost. My experience is that almost all patients and most families appreciate the opportunity to discuss these questions. Indeed, many have already made their decision. ${ }^{8}$
Third, we must be careful how we frame the discussion. It is not hard to persuade a patient to accept a medical intervention, especially in times of great stress. Late in the course of disease how different do the words "Would you like us to put a tube in him so he won't starve," sound when compared with, "At this point she can no longer swallow without food going into the lungs. The development of pneumonia and subsequent death is now only a matter of time. There are many things we can do, however, to make these last days or weeks comfortable and meaningful for her and your family. Would you like to talk about them?"

Fourth, we must be certain that we have the skills to manage these final stages of life. Access and willingness to use hospice services must be assured. Training in the management of pain and other symptoms, the relief of suffering, and how to deal with families must be a part of every resident's training and physician's commitment. For instance, recent studies have documented that the often-held belief that not providing parenteral nutrition is painful is wrong. ${ }^{9}$ Indeed, it is possible that we might increase suffering by forcing unwanted food or fluids on dying persons.

It is ironic that in the state where I live, the public has recently spoken loudly again that they want access to physician-assisted suicide; at the same time Grant has shown us that 1 out of 100 Americans of advanced age are going to their death beds with a feeding tube in their abdomen. I am sure that there is much ambivalence among physicians and consumers alike regarding the interventions used to stave off or promote death. ${ }^{10,11}$ But I would hope that we, as family physicians, can see that the true test of the physician is to support his or her patient during the dying process, to educate patients and families about the possibilities of meaningful growth and discovery that can come during this phase of the family life cycle, ${ }^{12}$ and to help the patient die a comfortable and natural death.

Kenneth Brummel-Smith, MD

Portland, Ore

\section{References}

1. Fuchs VR. Who shall live? Health, economics and social choice. New York: Basic Books, 1974.

2. Horton WL, Colwell DL, Burlon DT. Experience with percutaneous endoscopic gastrostomy in a community hospital. Am J Gastroenterol $1991 ; 86$ : 168-70.

3. Grant MD. Gastrostomies in older patients: The 
1990 National Hospital Discharge Survey. J Am Board Fam Pract 1998;11:187-92.

4. Ciocon JO, Silverstone FA, Graver LM, Foley CJ. Tube feedings in the elderly. Indications, benefits, and complications. Arch Intern Med 1988;148:429-33.

5. Rabeneck L, Wray NP, Petersen NJ. Long-term outcomes of patients receiving percutaneous endoscopic gastrostomy tubes. J Gen Intern Med 1996; 11:287-93.

6. Pick N, McDonald A, Bennett N, Litsche M, Dietsche L, Legerwood R, et al. Pulmonary aspiration in a long-term care setting: clinical and laboratory observations and an analysis of risk factors. J Am Geriatr Soc 1996;44:763-8.

7. Golden A, Beber C, Weber R, Kumar V, Musson N, Silverman $M$, et al. Long-term survival of elderly nursing home residents after percutaneous endoscopic gastrostomy for nutritional support. Nurs Home Med 1997;5:382-9.

8. Kohn M, Menon G. Life prolongation: views of elderly outpatients and health care professionals. J Am Geriatr Soc 1988;36:840-4.

9. Brody H, Campbell ML, Faber-Langendoen K, Ogle KS. Withdrawing intensive life-sustaining treatment- recommendations for compassionate medical management. N Engl J Med 1997;336:652-7.

10. Lee MA, Ganzini L, Brummel-Smith $K$. When patients ask about assisted suicide. A viewpoint from Oregon. West J Med 1996;165:205-8.

11. Solomon MZ, O'Donnell L, Jennings B, Guilfoy V, Wolf SM, Nolan K, et al. Decisions near the end of life: professional views on life-sustaining treatments. Am J Public Health 1993;83:14-23.

12. Levine $S$. Who dies? An investigation of conscious living and conscious dying. New York: Anchor Books, Doubleday, 1989.

\section{Alternative Medicine and the Family Physician}

Complementary and alternative medicine is a subset of health care practices that are not an integral part of the dominant health care system in the United States. ${ }^{1}$ Operationally, complementary and alternative medicine is defined as those health care practices used for the prevention and treatment of disease that neither are taught widely in medical schools nor are generally available in hospitals. ${ }^{2}$

Alternative medicine is an area of great public

Submitted 11 March 1998.

From the Office of Alternative Medicine, National Institutes of Health, Bethesda, Md. Address reprint requests to Wayne B. Jonas, MD, Office of Alternative Medicine, National Institutes of Health, 31 Center Dr, Building 31, Room 5B38, Mail Stop 2182, Bethesda, MD 20892. interest and activity, both nationally and worldwide. One of every three Americans saw an alternative health care practitioner in 1990, amounting to more than 400 million visits, more than to all conventional primary care physicians. More than $\$ 13$ billion were paid for these services, of which $\$ 10$ billion was out-of-pocket and not reimbursed. ${ }^{2}$ In Europe, regular use of complementary and alternative practices ranges from 20 to 70 percent. ${ }^{3}$ and nearly 40 percent in Australia. ${ }^{4}$ According to the World Health Organization, 80 percent of the health care services in the developing world are traditional medicine. ${ }^{5}$ These practices become complementary, alternative, or unconventional when used in Western countries. Recent surveys indicate that the use of complementary and alternative medicine is increasing. ${ }^{6}$

National surveys, however, though useful for understanding public health issues, can be misleading for physicians who deal with local populations or special groups. For example, up to 50 percent of patients who have cancer ${ }^{7}$ or are infected with human immunodeficiency virus ${ }^{8}$ will use unconventional practices at some point during the course of their illness. Folk medicine use in rural and special ethnic populations can exceed 70 percent, ${ }^{9}$ but in certain pediatric populations use of complementary and alternative medicine is around 10 percent. ${ }^{10}$

Although these population and condition-based surveys have documented widespread use of these practices, we know little about how frequently alternative medicine is used in the average family practice population, where a large portion of chronic disease care occurs. Information about the frequency, conditions, and reasons for use of complementary and alternative medicine by patients cared for in family practice can help the physician address these issues with patients more systematically and rationally. Thus, local surveys and surveys of special populations are needed. In this issue of the $7 A B F P$, Drs. Christine Drivdahl and William Miser ${ }^{11}$ report findings of a survey of a military family practice population that asked about the use, perceived effectiveness, and satisfaction of complementary and alternative medicine.

Drivdahl and Miser's report is a descriptive analysis of 177 (of 250) questionnaires randomly sent to persons eligible for care at a military family practice clinic in Washington state. The data showed that more than 28 percent of patients reported ever using alternative medicine. Examples 